\title{
Correction to: Non-linear Transfer Functions \\ for Accurately Estimating 3D Particle Size, \\ Distribution, and Expected Error from 2D Cross Sections of a Lognormal Distribution of Spherical Particles
}

\author{
A.R.C. GERLT, A.K. CRINER, S.L. SEMIATIN, K.N. WERTZ, and E.J. PAYTON
}

https://doi.org/10.1007/s11661-021-06406-2

(C) The Minerals, Metals \& Materials Society and ASM International 2021

Correction to: Metallurgical and Materials Transactions A, Volume 52A, January 2021 https://doi.org/10.1007/s11661-020-06072-w

THE original online version of this article has been corrected. There were errors in Eq. 26 and Fig. 9. In addition, several table and equation citations were corrected in the text.
Publisher's Note Springer Nature remains neutral with regard to jurisdictional claims in published maps and institutional affiliations.

A.R.C. GERLT is with the Air Force Research Laboratory, Wright-Patterson Air Force Base, OH 45433 and also with UES, Inc., 4401 Dayton-Xenia Road, Beavercreek, OH 45432. Contact e-mail: gerlt.1@buckeyemail.osu.edu A.K. CRINER, S.L. SEMIATIN, K.N WERTZ, and E.J. PAYTON are with the Air Force Research Laboratory, Wright-Patterson Air Force Base.

The original article can be found online at https://doi.org/10.1007/ s11661-020-06072-w.

Article published online August 19, 2021 